\title{
Deficient catecholamine release as the basis of orthostatic hypotension in pernicious anaemia
}

\author{
G EISENHOFER, DG LAMBIE, RH JOHNSON, ETH TAN, EA WHITESIDE \\ From the Dean's Department, Wellington Clinical School of Medicine, Wellington Hospital, Wellington, New \\ Zealand
}

SUMMARY A patient with peripheral neuropathy and orthostatic hypotension was found to have pernicious anaemia. Symptoms improved after vitamin $B_{12}$ replacement therapy. Insulin tolerance testing showed that the patient lacked catecholamine, heart rate, and sweating responses to hypoglycaemia. This indicates that pernicious anaemia may cause orthostatic hypotension owing to failure of noradrenaline release.

Pernicious anaemia is frequently accompanied by numerous CNS and peripheral nervous system abnormalities. These include pyramidal tract and posterior column dysfunction, optic neuropathy, and distal symmetric polyneuropathy with spinal cord involvement. ${ }^{1-3}$ Other disturbances include impotence, constipation, urinary retention and postural hypotension..$^{2-4}$ The causes of these have not been established, but could be due to autonomic neuropathy. We report a case of pernicious anaemia in which the presenting symptom was orthostatic hypotension. We have examined the pathophysiological basis of the orthostatic hypotension in this patient by measuring catecholamine and vasopressin responses to insulin-induced hypoglycaemia.

\section{Case history}

The patient was a 79-year-old male who complained of coldness and pins and needles sensations in the hands and feet, and dizziness on standing. He had fainting spells and occasionally broke out in a hot sweat. For six months these symptoms had progressively worsened, necessitating his admission to hospital. The patient complained that he had trouble initiating micturition and, after admission to hospital, constipation became a problem. The patient had given up smoking 10 years earlier, and was a light drinker.

On examination, no abnormalities were found in mental state or in the cranial nerves. His complexion was pale,

Address for reprint requests: Prof RH Johnson, Wellington Hospital, Wellington 2, New Zealand.

Received 17 May 1982

Accepted 28 June 1982 with a lemon-yellow tinge. Supine blood pressure and pulse rate were $130 / 50 \mathrm{mmHg}$ and $60 / \mathrm{min}$, respectively. Loss of sensation for pinprick was present to a clearly defined level above the knees in both legs, and above the wrists in both hands. The loss was bilaterally symmetrical. Decreased vibration sense in both legs was also apparent. A cervical spine radiograph revealed gross degenerative changes involving virtually all levels, with bony ankylosis between $\mathrm{C} 4$ and $\mathrm{C5}$, and narrowing of the spinal canal. Motor conduction velocities were normal in the right radial and median and lateral popliteal nerves. The ulnar median and sural sensory potentials were of low magnitude. On assumption of upright posture, blood pressure dropped from $130 / 50$ to $92 / 44 \mathrm{mmHg}$ at three minutes in the standing position, at which time the subject developed palor, dizziness and said he was going to faint. The heart rate responses to standing (increase of $22 / \mathrm{min}$ ) and to atropine (increase of $20 / \mathrm{min}$ ) were normal. An insulin tolerance test was carried out, with blood samples collected at 20,30,35, 40,45 and 60 min after intravenous injection of $0.1 \mathrm{unit} / \mathrm{kg}$ insulin. Samples were analysed for glucose, catecholamines and vasopressin. Catecholamines were measured using a radioenzymatic assay, as described previously. ${ }^{5}$ Vasopressin was measured by radioimmunoassay. Heart rate was measured before and after insulin at five-minute intervals. Sweat rate was assessed before and after insulin, measuring the change in weight of strips of filter paper taped across the forehead. Results were compared with those of six normal male control subjects (mean age $47 \mathrm{yr}$ ). Plasma glucose dropped $3.5 \mathrm{mM} / \mathrm{L}$ in control subjects and 3.0 $\mathrm{mM} / \mathrm{L}$ in the patient with pernicious anaemia. The patient exhibited a $3.0 \mathrm{pg} / \mathrm{ml}$ increase in plasma vasopressin, while control subjects had a $1.4 \mathrm{pg} / \mathrm{ml}$ increase (see fig). Plasma noradrenaline and adrenaline rose 0.4 and $0.8 \mathrm{ng} / \mathrm{ml}$, respectively, in control subjects; no response of plasma catecholamines was observed in the patient with pernicious 
anaemia (see fig). No changes in sweat rate or heart rate were observed in this patient compared with a mean increase in heart rate of $15 / \mathrm{min}$, and a 13 -fold increase in sweat rate for control subjects. There was no evidence of diabetes mellitus. Plasma glucose and the response to glucose tolerance test were normal. Urea, electrolytes and liver function tests were within normal limits. Thyroid function studies indicated a euthyroid state. Blood count showed anaemia-haemoglobin of $101 \mathrm{~g} / \mathrm{l}$, with a reduced haematocrit $(0 \cdot 30)$ and elevated MCV $(115 \mathrm{fl})$. A vitamin $B_{12}$ deficiency was suspected, and this was confirmed with the findings of a vitamin $B_{12}$ level of $50 \mathrm{pmol} / 1$ (normal range $160-600 \mathrm{pmol} / \mathrm{l})$. Serum folate and red cell folate were both normal.

The patient was commenced on vitamin $B_{12}$ injections, $1000 \mu \mathrm{g}$ intramuscularly every second day. He was dis-
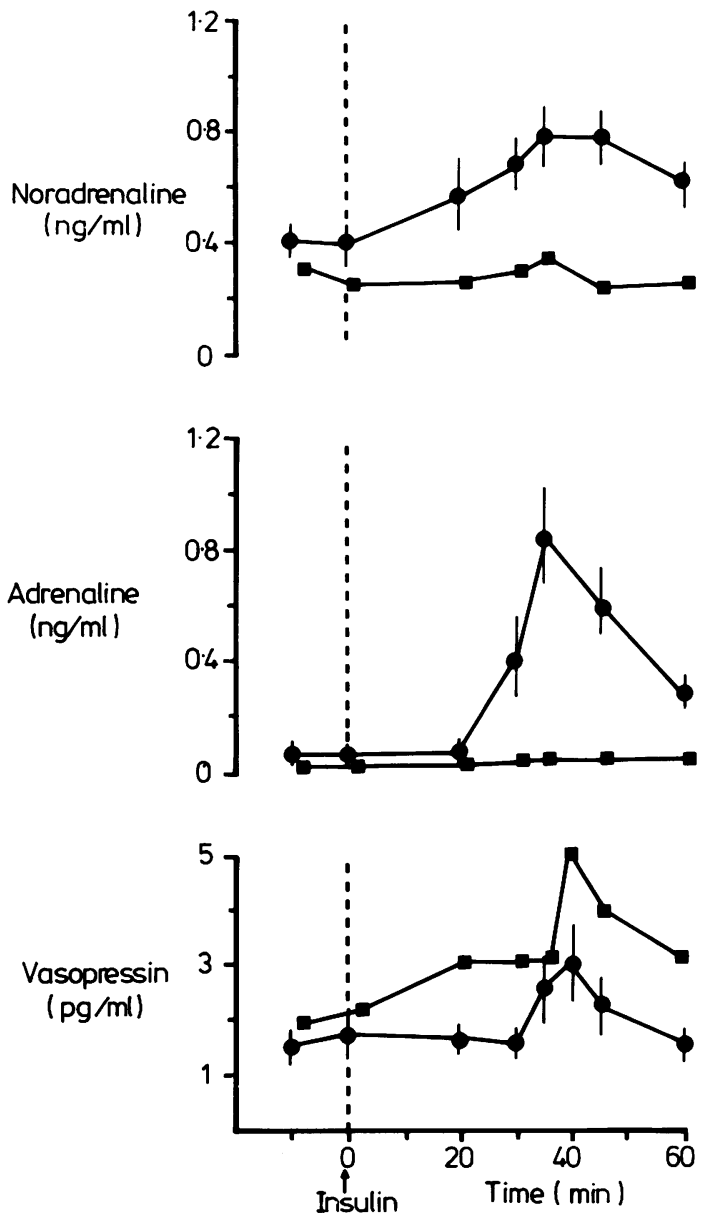

Figure Plasma noradrenaline, adrenaline and vasopressin responses to intravenous insulin $(0.1 \mathrm{u} / \mathrm{kg})$ in six control subjects (circles, mean $\pm S E M$ ) and patient with pernicious anaemia (squares). charged 17 days after admission, at which time the orthostatic hypotension and other symptoms of peripheral neuropathy had improved. Monthly vitamin $B_{12}$ injections were continued after discharge. At two months after discharge his haemoglobin had increased to $110 \mathrm{~g} / \mathrm{l}$ and his condition was much improved although, even after nine months, some degree of paraesthesia and coldness were still present in the extremities.

\section{Discussion}

Peripheral neuropathy is common in pernicious anaemia, and both segmental demyelination and axonal degeneration ${ }^{36}$ have been identified histopathologically. Recently, a case of pernicious anaemia was described where the presenting symptom was postural hypotension, ${ }^{4}$ previously unreported in vitamin $B_{12}$ deficiency. Postural hypotension was suggested to be due to autonomic neuropathy, but there were no physiological studies to confirm this.

Postural hypotension may result from a number of causes, including diminished blood volume, obstruction of venous return or neurological disease with disordered circulatory reflexes. ${ }^{7}$ Postural hypotension associated with the last named is a feature of diabetes mellitus ${ }^{8}$ or primary autonomic failure. ${ }^{9}$ The lesion causing orthostatic hypotension in these conditions involves the abnormal release of noradrenaline from the sympathetic nerves involved in the vasoconstrictor response to upright posture. ${ }^{89}$ Absent noradrenaline and adrenaline responses to insulin hypoglycaemia may also be observed in sympathetic failure. ${ }^{10}$

Since our patient was able to stand only briefly at the time of investigation, we assessed noradrenaline and adrenaline responses by insulin tolerance testing. Not only did the patient lack catecholamine responses, but he also showed no changes in heart rate. These results indicate a lesion in the sympathetic nervous system. Hence, postural hypotension resulted from lack of catecholamine-mediated vasoconstriction responses to upright posture. The normal rèsponses of heart rate to standing and to atropine indicates that the parasympathetic nervous system was not involved.

Some patients with the Shy-Drager syndrome and orthostatic hypotension have been found to have abnormal vasopressin release. ${ }^{1112}$ The patient reported here exhibited a vasopressin response to hypoglycaemia, indicating that absence of catecholamine responses was not due to failure of central brain receptors to respond to hypoglycaemia. Orthostatic hypotension and other symptoms improved after vitamin replacement therapy. This indicates that nervous damage was secondary to vitamin $B_{12}$ deficiency, and that absent 
catecholamine responses were a secondary functional disturbance of this deficiency.

\section{References}

${ }^{1}$ Mayer RF. Peripheral nerve function in vitamin $B_{12}$ deficiency. Arch Neurol 1965;13:355-62.

${ }^{2}$ Wieck HH. Funiculare spinalerkrankungen und B12avitaminotische psychose. Med Klin 1967;62:767-70.

${ }^{3}$ Kunze K, Leitemaier K. Vitamin $B_{12}$ deficiency and subacute combined degeneration of the spinal cord. In: Vinken PJ, Bruyn GW, eds. Handbook of Clinical Neurology. New York: American Elsevier Co, 1976; vol28:141-98.

4 White WB, Reik L, Cutlip DE. Pernicious anaemia seen initially as orthostatic hypotension. Arch Intern Med $1981 ; 141: 1543-4$.

${ }^{5}$ Peuler JD, Johnson GA. Simultaneous single isotope radioenzymatic assay of plasma norepinephrine, epinephrine and dopamine. Life Sci 1977;21:625-36.

- Smith WT. Nutritional deficiencies and disorders. In: Blackwood W, Corsellis JAN, eds. Greenfield's
Neuropathology. London: Edward Arnold, 1976:194-237.

7 Johnson RH, Spalding JMK. Arterial hypotension. In: Disorders of the autonomic nervous system. Philadelphia: FA Davis Co, 1974:79-113.

${ }^{8}$ Cryer PE, Silverberg AB, Santiago JV, Shah SD. Plasma catecholamines in diabetes: the syndromes of hypoadrenergic and hyperadrenergic postural hypotension. Am J Med 1978;64:407-16.

${ }^{9}$ Ziegler MG, Lake CR, Kopin IJ. The sympatheticnervous system in primary orthostatic hypotension. New Eng J Med 1977;296:293-7.

${ }^{10}$ Polinsky RJ, Kopn IJ, Ebert MH. Hormonal responses to hypoglycaemia in orthostatic hypotension patients with adrenergic insufficiency. Life Sci 1981;29:41725.

${ }^{11}$ Lockwood AH. Shy-Drager syndrome with abnormal respirations and antidiuretic hormone release. Arch Neurol 1976;33:292-5.

12 Wilcox CS, Aminoff MJ, Penn W. Basis of nocturnal polyuria in patients with autonomic failure. $J$ Neurol Neurosurg Psychiatry 1974;37:677-84. 